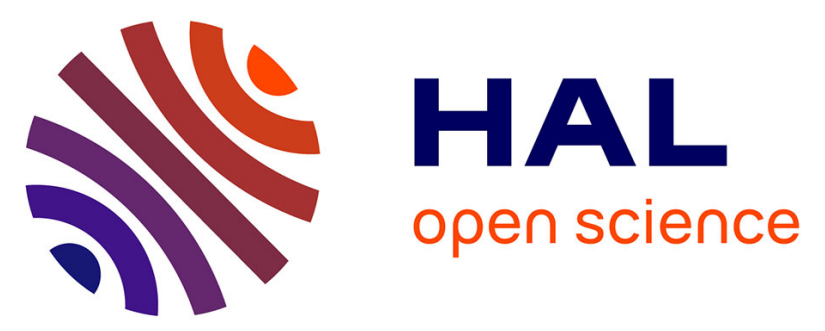

\title{
Diagnostic accuracy of lung ultrasound for identification of elevated left ventricular filling pressure
} Arnaud Hubert, Nicolas Girerd, Hervé Le Breton, Elena Galli, Ichraq Latar, Maxime Fournet, Philippe Mabo, Frédéric Schnell, Christophe Leclercq, Erwan Donal

\section{To cite this version:}

Arnaud Hubert, Nicolas Girerd, Hervé Le Breton, Elena Galli, Ichraq Latar, et al.. Diagnostic accuracy of lung ultrasound for identification of elevated left ventricular filling pressure. International Journal of Cardiology, 2019, 281, pp.62-68. 10.1016/j.ijcard.2019.01.055 . hal-02049698

\section{HAL Id: hal-02049698 \\ https://hal-univ-rennes1.archives-ouvertes.fr/hal-02049698}

Submitted on 18 Dec 2019

HAL is a multi-disciplinary open access archive for the deposit and dissemination of scientific research documents, whether they are published or not. The documents may come from teaching and research institutions in France or abroad, or from public or private research centers.
L'archive ouverte pluridisciplinaire HAL, est destinée au dépôt et à la diffusion de documents scientifiques de niveau recherche, publiés ou non, émanant des établissements d'enseignement et de recherche français ou étrangers, des laboratoires publics ou privés. 


\section{Diagnostic accuracy of Lung Ultrasound for identification of elevated left ventricular filling pressure}

Arnaud Hubert, M.D. ${ }^{1,2,3}$, Nicolas Girerd, M.D., PhD. ${ }^{4}$, Hervé Le Breton, M.D., PhD. ${ }^{1,2,3}$, Elena Galli, M.D., PhD. ${ }^{1,2,3}$, Ichraq Latar ${ }^{4}$, Maxime Fournet, M.D. ${ }^{1,2,3}$, Philippe Mabo, M.D. ${ }^{1,2,3}$

Frederic Schnell M.D., PhD. 1,2,5, Christophe Leclercq, M.D., PhD. 1,2,3, Erwan Donal, M.D., PhD. ${ }^{1,2,3}$

1 CHU Rennes, Service de Cardiologie et Maladies Vasculaires et CIC-IT 1414, Rennes, 35000, France

2 Université de Rennes 1, LTSI, Rennes, 35000, France

3 INSERM, U1099, Rennes, 35000, France

4 INSERM, Centre d'Investigations Cliniques 1433, Université de Lorraine, CHU de Nancy, Institut Lorrain du Cœur et des Vaisseaux, Nancy, France and INI-CRCT (Cardiovascular and Renal Clinical Trialists) F-CRIN network, Nancy, France.

5 CHU Rennes, Service de Médecine du Sport, Rennes, 35000, France

\section{Corresponding author:}

Erwan Donal,

Service de Cardiologie et Maladies Vasculaires

CHU de Rennes

2 rue Henri Le Guilloux, 35000 Rennes, France.

E-mail: erwan.donal@chu-rennes.fr

Type: Original Research 
Abstract: (193 words)

Aims: The current algorithm in transthoracic echocardiography (TTE) proposed in the 2016 ASE/EACVI recommendation for the estimation of left ventricular filling pressure (LVFP) is quite complex and time-consuming. B-lines, in lung ultrasonography (LUS), could constitute an interesting tool for LVFP evaluation in clinical practice, although data regarding their association with invasive haemodynamics are lacking. The purpose of this study was to explore the diagnostic accuracy of B-lines in identifying elevated left ventricular end-diastolic pressure (LVEDP).

Method and results: 81 adults with significant dyspnoea (NYHA $\geq 2$ ) were prospectively analyzed by LUS in four areas in each hemithorax and a complete TTE within four hours prior to coronary angiography. Twenty-eight patients had elevated LVEDP. Clinical variables yielded a C-index of $79 \%$ to identify elevated LVEDP. The number of total B-lines was higher in the elevated LVEDP group (1.0vs17.0, p<0.0001) and significantly increased the diagnostic accuracy $(\mathrm{C}$-index increase $=10.5 \%, \mathrm{p}=0.002)$ and net reclassification index $(\mathrm{NRI}=145.4,113.0$ $177.9, \mathrm{p}<0.0001)$ on top of clinical variables.

Conclusion: This study demonstrates the substantial diagnostic capacity of B-lines to identify elevated LVEDP, which appears superior to that of classical echocardiographic strategies. This tool should be considered in a multi-parametric approach in patients with heart failure.

\section{Conflicts of interests: None}

$\underline{\text { Running title: }}$ B-lines and left ventricular filling pressure

Keywords: B-lines, lung ultrasonography, left ventricular filling pressure, echocardiography Word count (without tables and figures): 4415 words 


\section{Introduction}

Echocardiography is currently the gold standard in the routine evaluation of left ventricular filling pattern in patients with dyspnoea and/or heart failure. The 2016 American Society of Echocardiography (ASE) and European Association of Cardiovascular Imaging (EACVI) guidelines for the evaluation of left ventricular diastolic function[1] reported a new algorithm to assess the presence and severity (grade 1 to 3 ) of diastolic dysfunction (DD) and to estimate Left Ventricular Filling Pressure (LVFP). This algorithm, based on the estimation of left atrial volume, E wave, velocity, e' septal and lateral velocity by Tissue Doppler Imaging (TDI), and maximal tricuspid velocity is quite complex and time-consuming.

B-lines (also called "comet-tail artefacts" or "lung comet") are linear artefacts that are observed during lung ultrasonography (LUS), reflecting extravascular lung water [2]. LUS is simple and can be applied quickly at a patient's bedside with the same probe that is used for echocardiography. The utility of B-line quantification for the diagnosis of acute pulmonary oedema has been demonstrated in multiple studies. B-line number shows a good correlation with chest radiography findings, brain natriuretic peptide levels and E/e' ratio [3-6]. In patients with subclinical pulmonary congestion, the assessment of B-lines allows the diagnosis of subclinical pulmonary congestion and is strongly associated with clinical outcome[7-9]. With regard to the ASE/EACVI joint recommendations which can be difficult to apply in the presence of severe valvulopathy and/or atrial fibrillation, B-line quantification can be performed in these clinical conditions and is associated with clinical outcome regardless of underlying heart disease [10]. Moreover, echocardiographic algorithms are influenced by ageing given its strong association with diastolic function impairment; this may decrease the diagnostic accuracy for elevated LVFP in these patients[11]. B-lines could therefore constitute a valuable bedside tool for LVFP evaluation in routine clinical practice. A previous study[12] reported a good association of B-line count and right catheter haemodynamics although did not 
evaluate diagnostic accuracy per se and included mostly young patients (a third of the patients were included after heart transplant). Data regarding the association between B-lines and left cardiac haemodynamics in non-transplanted elderly patients are still lacking.

The purpose of this study was to explore the diagnostic accuracy of B-lines to identify elevated left ventricular end-diastolic pressure (LVEDP), as assessed by left heart catheterization (LHC).

\section{Methods}

\section{Study sample}

We prospectively included 93 adults ( $\geq 18$ years old) with significant dyspnoea (NYHA $\geq 2$ ) who underwent a coronary angiography with left heart catheterization from May 2016 to July 2017. Patients with mitral stenosis (because of significant differences in LVEDP compared to other heart disease), known pulmonary fibrosis, pneumonia, active lung cancer or a history of recent chest trauma were excluded. Patients who had any change in diuretic treatment between Transthoracic Echocardiography (TTE) and LHC were also excluded. These exclusion criteria were chosen among conditions that alter B-line counting[13]. Clinical and demographic data were obtained from the review of medical records. N-terminal Pro-Brain Natriuretic Peptide (NT-ProBNP) testing was performed within routine care prior to the angiography and recorded when available. The study protocol was approved by our local ethics committee (authorization number: 2014-A01331-456).

\section{Transthoracic Echocardiography}

All patients underwent a standard TTE prior to LHC using a Vivid S6, E7 or E9 ultrasound system (General Electric Healthcare, Horten, Norway). Images were recorded on a remote station for off-line analysis by dedicated software (EchoPAC PC, version BT 13, General Electric Healthcare, Horten, Norway). Interpretation was blinded from haemodynamic 
data. Left ventricular ejection fraction (LVEF) was measured by biplane Simpson's method, and $\mathrm{LVEF} \geq 50 \%$ was considered to constitute a preserved ejection fraction [14]. Typical diastolic parameters were measured: peak tricuspid regurgitation velocity, right atrial pressure estimated by inferior vena cava diameter and collapsibility, mitral LV inflow early peak (E) with the deceleration time and late peak (A), isovolumic relaxation time (IVRT), septal and lateral diastolic early peak velocity of mitral annulus (e') and left atrial volume index $(\mathrm{LAVi})[1]$

\section{Lung Ultrasonography}

Lung ultrasonography was performed immediately before a comprehensive TTE with patients in supine or near-to-supine position, as previously described [2]. Four different areas for each hemithorax were explored during five seconds (Figure 1, panel B-1). The probe was placed in sagittal orientation, in the intercostal space, at an imaging depth of 10 to $14 \mathrm{~cm}$. Loops were recorded in order to maximize the number of B-lines for each zone by adjusting the gain to allow for optimal visualization of the pleural line and B-lines (Figure 1, panel B-2). The scanning lasted less than 3 minutes. Loops were stored on a remote station to perform off-line analysis with the same tools as those used for TTE. For each lung ultrasound zone, the number of B-lines was quantified from 0 to 10 . Consequently, LUS scoring ranged from 0 to 80 (8zones method). B-line count was used either as a continuous variable or dichotomized using the following cut-offs: 1) 3 , which has been reported to be the best cut-off for the prediction of stable heart failure (HF) patient outcomes[7,15], 2) 8, which approximately corresponds to a score of 30 when using the 28-points method, a useful cut-off in patients at discharge from HF hospitalization[16], and 3) the presence of one or two bilateral positive zones (> 2 B-lines on a recording site) as promoted by acute LUS guidelines [13] (Figure 1, panel B-3). 


\section{Haemodynamic data}

LHC was performed, within four hours after TTE, via a retrograde approach from the radial artery. Before coronary angiography, transducers were calibrated, with a 0-level set at the mid-axillary line. The LVEDP was recorded continuously $(25 \mathrm{~mm} / \mathrm{s})$ with a 5 French Judkin R4 catheter (ICU Medical, San Clemente, CA, USA) placed at the mid-LV cavity using fluoroscopic screening. Waveform analysis was performed from paper tracings and was blinded from lung and heart ultrasonographic data. The LVEDP was calculated as the mean value of 4 consecutive heart cycles.

An elevated LVEDP was defined by a LVEDP > $20 \mathrm{mmHg}$ [17]. In our experience, a LVEDP cut-off of $16 \mathrm{~mm} \mathrm{Hg}$ is not strongly associated with symptoms and signs of congestion.

\section{Inter- and intra-observer variability}

Interpretation of LUS loops was repeated in 10 random patients $(>10 \%$ of the total population). An inter-observer reproducibility assessment was performed by 4 independent observers. For the intra-observer reproducibility assessment, the second reading was performed at least 2 months after the initial evaluation. During these repeated measurements, all observers were blinded to previous analysis and were unaware of patient clinical and haemodynamic data.

\section{Statistical analysis}

Continuous data are presented as the mean \pm standard deviation, and categorical data are presented as numbers. The distributions of variables were assessed visually. Comparisons between both groups (LVEDP $\leq 20 \mathrm{~mm} \mathrm{Hg}$ or $>20 \mathrm{~mm} \mathrm{Hg}$ ) were performed using an unpaired t-test or a Mann-Whitney test for continuous variables and a $\chi^{2}$ test or Fisher's exact test for categorical variables, as appropriate. Correlation between parameters and LVEDP was tested by a Spearmen test. Receiver operating characteristic (ROC) curves were created and areas 
under the curves (AUC) were calculated for the ability of each parameter to identify patients with a LVEDP > $20 \mathrm{mmHg}$. In addition, continuous net reclassification improvement (NRI) was performed to assess the additional value of ultrasonography parameters on top of clinical variables in predicting LVEDP> $20 \mathrm{mmHg}$. A diagnostic accuracy increase on top of these clinical variables was assessed using C-index differences extracted from logistic models.

Inter- and intra-observer variabilities of B-line counting were expressed by intra-class correlation coefficients.

Tests with p-values less than 0.05 were considered to be statistically significant.

Statistical analysis was performed using SAS (SAS institute, North Carolina, US).

\section{Results}

\section{Patient characteristics}

Among the 81 analysed patients (Figure 1, panel A), 28 had elevated LVEDP (Table 1). Patients with elevated LVEDP were more likely to have diabetes, chronic obstructive pulmonary disease (COPD) and heart failure. There were no significant differences in the proportion of history of chronic kidney disease, severe heart valve diseases, atrial fibrillation (AF) and coronary disease.

\section{Differences in lung and heart ultrasonography variables according to LVEDP}

A marked difference was identified in B-line count according to LVEDP level (median B-line count $1.0(0.0$ - 4.0) in patients with LVEDP<20 vs. $17.0(9.0$ - 24.0) in patients with LVEDP $\geq 20 \mathrm{mmHg}, \mathrm{p}<0.0001$, Table 2). This significant difference persisted upon dichotomization of B-lines (all p<0.001). The 8 B-line cut-offs yielded marginally fewer true positive patients than the 3 B-line cut-offs (78.6\% vs. $85.7 \%$, respectively) although with numerous fewer false positives ( $9.4 \%$ vs. $34 \%$, respectively). 
Overall, LV diastolic parameters were more impaired in the elevated LVEDP group (Table 2): E/A ratio and average mitral E/é ratio were higher (1.3 vs. $0.8, \mathrm{p}=0.001$ and 15.6 vs. 11.6, $\mathrm{p}=0.014$, respectively), and $\mathrm{E}$ wave deceleration time and isovolumic relaxation time were shorter (167 vs. $216 \mathrm{~ms}, \mathrm{p}=0.004$ and 106.3 vs. $125.0 \mathrm{~ms}, \mathrm{p}=0.035$, respectively). Of note, LAVi was not significantly different across groups (45.7 vs. $\left.49.1 \mathrm{ml} . \mathrm{m}^{-2}, \mathrm{p}=0.51\right)$.

The following parameters were significantly higher in the elevated LVEDP group: peak Tricuspid Regurgitation (TR) velocity $\left(2.9 \pm 0.6 \mathrm{~cm} . \mathrm{s}^{-1}\right.$ vs. $\left.2.5 \pm 0.4, \mathrm{p}=0.002\right)$, inferior vena cava diameter $(18.5 \mathrm{~mm}$ vs. $11.0, \mathrm{p}<0.0001)$ and estimated systolic pulmonary artery pressure $(50.0$ vs. $30.0 \mathrm{mmHg}, \mathrm{p}=0.0007)$.

Correlation of lung and heart ultrasonography variables with LVEDP

The correlation between B-line count and LVEDP was higher than that observed for all echocardiographic parameters $(\mathrm{r}=0.62$ for $\mathrm{B}$-line count vs. $\mathrm{r}<0.50$ for all right- or left-sided echocardiographic parameters, Table 3). Among LV parameters, the highest correlation was observed for E/A ratio $(\mathrm{r}=0.338)$. Peak tricuspid regurgitation velocity, inferior vena cava diameter and estimated systolic pulmonary artery pressure exhibited correlations with LVEDP ranging from 0.40 to 0.50 .

Diagnostic accuracy for elevated LVEDP of lung and heart ultrasonography variables (Figure 1-panel C)

None of the clinical and echocardiographic parameters significantly increased the diagnostic accuracy for elevated LVEDP in addition to clinical variables (namely, age, NYHA class, signs of pulmonary congestion, diabetes, COPD and history of heart failure) except for IVC diameter [C-Index increase of 7.1 (0.3 to 14.0), $\mathrm{p}=0.042$, Table 3] and PASP [C-Index increase of 6.3 (0.2 to 12.5$), \mathrm{p}=0.043]$. Importantly, NtProBNP was also not associated with a 
significant increase in $\mathrm{C}$-index $(\mathrm{C}$-Index increase of 0.8 (-5.6 to 7.2), $\mathrm{p}=0.81)$. In contrast, $\mathrm{B}$ line count used either as a continuous or dichotomous variable significantly increased the diagnostic accuracy [C-index increase of 10.5 (3.7 to 17.3), $\mathrm{p}=0.002$ for total B-line count; 5.9 (-0.1 to 11.9$), \mathrm{p}=0.053$ for $\mathrm{B}$-lines $\geq 3 ; 8.6$ (2.4 to 14.8$), \mathrm{p}=0.007$ for B-lines $\geq 8$, Table 3 ]. The diagnostic accuracy obtained with the joint use of clinical variables and B-lines was excellent [C-index $=95.5$ (90 to 100)]. These results remained consistent in subgroup analysis in the AF population or decreased ejection fraction (LVEF $<30 \%$; LVEF $<40 \%$ ) (table in supplementary materials 2).

Reclassification was not significantly increased when using left-sided recorded ultrasonography parameters. In contrast, IVC diameter, peak tricuspid regurgitation velocity and estimated systolic pulmonary arterial pressures as well as lung ultrasonography parameters significantly increased reclassification.

Of note, the integration of the last recommendations in the evaluation of LV pressure did not increase either the reclassification [NRI 45.0 (-5.6 to 95.6), $\mathrm{p}=0.081$ ] or diagnostic accuracy [C-index increase of $-0.2(-1.6$ to 1.3$), p=0.82]$.

Lastly, intra- and inter-observer reproducibility was excellent, with ICCs $>0.9$ for both measurements (graphs in supplementary materials).

\section{Discussion}

In this study, B-line count as measured by lung ultrasonography (LUS) was the variable most strongly correlated with invasively measured LVEDP, and significantly increased both diagnostic accuracy and reclassification for elevated LVEDP. Strikingly, none of the left-sided recorded echocardiographic parameters correlated well with LVEDP or were associated with a similarly important increase in diagnostic accuracy for elevated LVEDP. In contrast, peak TR velocity and vena cava diameter were moderately correlated with LVEDP, while IVC diameter 
significantly increased the diagnostic accuracy for elevated LVEDP. Taken together, these results suggest the usefulness of LUS and IVC diameter quantification for evaluating LV filling pressures.

\section{Lung ultrasonography to identify elevated filling pressures}

Our study is the first to demonstrate an association between elevated LVEDP measured by LHC and B-line count. In a previous study, Platz et al., reported a fair association of B-line count with right-sided haemodynamic variables [12], whereas no significant association was identified with wedge pressures. In contrast, in the present study, we found a moderate association between B-line count and LV filling pressures. The mismatch between wedge pressures and pulmonary congestion observed in some patients [18] could account for these discrepancies. Furthermore, Halpern et al. recently questioned the relevance of wedge pressure to correctly classify pre- and post-capillary hypertension[19]; thereby casting some doubt on the ability of wedge pressure to appropriately identify pulmonary oedema. Consequently, our study strengthens the case of LUS for the correct assessment of heart haemodynamics that are relevant for congestion evaluation (i.e., LVEDP).

A 28-zone LUS is usually used in ambulatory or hospitalized patients with heart failure during their hospital stay $[6,10,16]$. In this study, we used a simplified technique using 8 scanning zones, similar to the imaging strategy used by Platz et al. in ambulatory patients[12]. However, B-line quantification using a score graded on a scale of 80 was used as opposed to the diagnosis algorithm used in the emergency department. The strong association and diagnostic accuracy of this semi-quantitative simplified technique, which can be performed in a few minutes, suggest its adequacy for routine clinical practice. The finding of $0.3 \mathrm{~B}$-lines or more per scanning site does appear as a reliable threshold to identify high-risk ambulatory HF patients[7,15,20] (adjusted hazard ratio for death or hospitalization for HF 4.08, 1.95-8.54; 
$\mathrm{p}<0.001)$. Our study provides the haemodynamic background for this observation as patients with $0.3 \mathrm{~B}$-lines or more are very likely to have a LVEDP higher than $20 \mathrm{mmHg}$.

On the other hand, the use of 8 B-lines as a cut-off for a 28-point technique (i.e., a similar 0.3 B-lines per scanning site) could provide similar diagnostic accuracy with a reduced risk of misclassification[15], but at the expense of a moderately longer acquisition time.

\section{Echocardiography to identify elevated filling pressures}

IVC diameter and peak TR velocity were found to be relevant markers of elevated LVEDP. Ommen et al. demonstrated a clear correlation between IVC diameter and right atrial pressure [21] that could be increased as a result of LV diastolic dysfunction, hypervolemia or both. Peak TR velocity is a marker of elevated pulmonary artery systolic pressure (PASP). Transthoracic echocardiography ascertains the pre- or post-capillary status of pulmonary hypertension [22]; however, postcapillary hypertension is the most frequent in patients with HF and/or LV diastolic dysfunction [23]. When associated with LUS, and based on the results of our study, IVC does appear to be the best candidate to identify elevated LVEDP since it was the only parameter to significantly increase diagnostic accuracy on top of clinical variables.

\section{Weaknesses of traditional LV echocardiographic parameters to identify LVEDP}

Typical markers of LV diastolic dysfunction that are used as individual markers did not effectively identify elevated LVEDP. In addition to an international study by Sato et al. [24], Lancellotti et al., in a recent multicentre European study [25], reported concurring results. Most importantly, the algorithm recommended in the 2016 ASE/EACVI recommendations yielded only a moderate performance for elevated LVEDP (C-index 0.78 ). In our study, the diagnostic accuracy of clinical variables (C-index 0.79) was similar to that of clinical variables and the 
2016 ASE/EACVI algorithm (C-index 0.79), suggesting that the algorithm has no additional clinical relevance to better assess congestion in patients with HF. This result further adds to the ongoing debate regarding the usefulness of current algorithms to identify elevated LV filling pressures [26,27].

The poor diagnostic capacity of the aforementioned algorithm in our cohort could be the consequence of the limitations of echocardiographic evaluation: high E-wave velocity can be observed in patients with mitral regurgitation, e' can be altered by mitral annulus calcifications rather than LV filling pressures, etc. For LA volume, numerous confounding factors could increase atrial size including AF (approximately 30\% of the study population), mitral insufficiency or aortic stenosis. LA volume seemingly constitutes more of a LV remodelling marker than a LV filling marker, except for a highly selected population. In contrast, LUS is not influenced by these cardiac conditions, which in turn could translate into better diagnostic accuracy.

\section{Clinical implications}

B-lines are an efficient marker of elevated LVFP. Consequently, they should be more frequently implemented in the assessment of LV diastolic function and LVFP. Their implementation could moreover be extremely easy in routine practice, either prior to or immediately after transthoracic echocardiography, and could be completed within less than 3 minutes.

In addition, because of the portability of recently introduced hand-held devices, LUS could further be easily performed throughout the course of in-hospital management or in the outpatient setting. We do believe, as other authors $[10,28,29]$, that LUS is more accurate than lung auscultation [30,31] and should thus be routinely performed in patients with HF as an 
extension of clinical examination. Whether this powerful diagnostic tool can help better tailor HF treatment and improve clinical outcomes remains to be tested in clinical trials.

\section{Limitations}

Limitations of this study include its single-centre nature and moderate sample size. Results herein should therefore be interpreted with caution and warrant confirmation in larger multicentre studies.

LVEDP was considered to be the gold standard in our study although some authors consider that the mean LAP provides a better estimation of pulmonary congestion [32]. However, rather than including patients with AF in whom LAP usefulness is questionable, LVEDP was preferentially used as the outcome of our study. In addition, patients with mitral stenosis were excluded in order to decrease the risk of error in filling pressure estimation using LVEDP.

B-lines can have non-cardiogenic origin. Although patients with a high risk of false positive LUS exams (pulmonary fibrosis, etc.) were excluded, we cannot rule out the possibility that some of the patients included in this cohort had B-lines of non-cardiac origin. However, despite these potential measurement caveats, LUS yielded an excellent diagnostic accuracy for elevated LVEDP.

\section{Conclusion}

This study demonstrates the important diagnostic capacity of B-lines in identifying elevated left ventricular end-diastolic pressure. This tool should be considered in a multi-parametric approach of patients with HF. The simplicity of LUS and IVC diameter measurement allows the use of a hand-held device to quickly, easily and adequately evaluate LV filling pressure. 


\section{Acknowledgements:}

We thank Jean-Loup Machu for the statistical editing of the manuscript. 


\section{Bibliography}

[1] S.F. Nagueh, O.A. Smiseth, C.P. Appleton, B.F. Byrd, H. Dokainish, T. Edvardsen, F.A. Flachskampf, T.C. Gillebert, A.L. Klein, P. Lancellotti, P. Marino, J.K. Oh, B.A. Popescu, A.D. Waggoner, Recommendations for the Evaluation of Left Ventricular Diastolic Function by Echocardiography: An Update from the American Society of Echocardiography and the European Association of?Cardiovascular Imaging, J. Am. Soc. Echocardiogr. 29 (2016) 277-314. doi:10.1016/j.echo.2016.01.011.

[2] E. Picano, F. Frassi, E. Agricola, S. Gligorova, L. Gargani, G. Mottola, Ultrasound lung comets: a clinically useful sign of extravascular lung water, J. Am. Soc. Echocardiogr. Off. Publ. Am. Soc. Echocardiogr. 19 (2006) 356-363. doi:10.1016/j.echo.2005.05.019.

[3] Z. Jambrik, S. Monti, V. Coppola, E. Agricola, G. Mottola, M. Miniati, E. Picano, Usefulness of ultrasound lung comets as a nonradiologic sign of extravascular lung water, Am. J. Cardiol. 93 (2004) 1265-1270. doi:10.1016/j.amjcard.2004.02.012.

[4] L. Gargani, F. Frassi, G. Soldati, P. Tesorio, M. Gheorghiade, E. Picano, Ultrasound lung comets for the differential diagnosis of acute cardiogenic dyspnoea: A comparison with

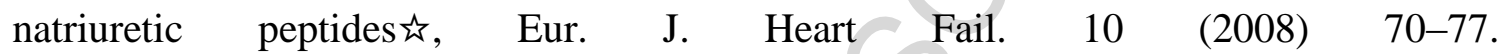
doi:10.1016/j.ejheart.2007.10.009.

[5] F. Frassi, L. Gargani, P. Tesorio, M. Raciti, G. Mottola, E. Picano, Prognostic Value of Extravascular Lung Water Assessed With Ultrasound Lung Comets by Chest Sonography in Patients With Dyspnea and/or Chest Pain, J. Card. Fail. 13 (2007) 830-835. doi:10.1016/j.cardfail.2007.07.003.

[6] M.H. Miglioranza, L. Gargani, R.T. Sant'Anna, M.M. Rover, V.M. Martins, A. Mantovani, C. Weber, M.A. Moraes, C.J. Feldman, R.A.K. Kalil, R. Sicari, E. Picano, T.L.L. Leiria, Lung Ultrasound for the Evaluation of Pulmonary Congestion in Outpatients: A Comparison With Clinical Assessment, Natriuretic Peptides, and Echocardiography, JACC Cardiovasc. Imaging. 6 (2013) 1141-1151. doi:10.1016/j.jcmg.2013.08.004.

[7] E. Platz, E.F. Lewis, H. Uno, J. Peck, E. Pivetta, A.A. Merz, D. Hempel, C. Wilson, S.E. Frasure, P.S. Jhund, S. Cheng, S.D. Solomon, Detection and prognostic value of pulmonary congestion by lung ultrasound in ambulatory heart failure patients $\dagger$, Eur. Heart J. (2016). doi:10.1093/eurheartj/ehv745.

[8] M.H. Miglioranza, E. Picano, L.P. Badano, R. Sant'Anna, M. Rover, F. Zaffaroni, R. Sicari, R.K. Kalil, T.L. Leiria, L. Gargani, Pulmonary congestion evaluated by lung ultrasound predicts decompensation in heart failure outpatients, Int. J. Cardiol. 240 (2017) 271-278. doi:10.1016/j.ijcard.2017.02.150.

[9] C. Cogliati, G. Casazza, E. Ceriani, D. Torzillo, S. Furlotti, I. Bossi, T. Vago, G. Costantino, N. Montano, Lung ultrasound and short-term prognosis in heart failure patients, Int. J. Cardiol. 218 (2016) 104-108. doi:10.1016/j.ijcard.2016.05.010.

[10] S. Coiro, G. Porot, P. Rossignol, G. Ambrosio, E. Carluccio, I. Tritto, O. Huttin, S. Lemoine, N. Sadoul, E. Donal, F. Zannad, N. Girerd, Prognostic value of pulmonary congestion assessed by lung ultrasound imaging during heart failure hospitalisation: A two-centre cohort study, Sci. Rep. 6 (2016). doi:10.1038/srep39426.

[11] E.G. Abinader, D.S. Sharif, Influence of age on Doppler echocardiographic indices of left ventricular diastolic function, Br. Heart J. 61 (1989) 483.

[12] E. Platz, A. Lattanzi, C. Agbo, M. Takeuchi, F.S. Resnic, S.D. Solomon, A.S. Desai, Utility of lung ultrasound in predicting pulmonary and cardiac pressures, Eur. J. Heart Fail. 14 (2012) 1276-1284. doi:10.1093/eurjhf/hfs144. 
[13] G. Volpicelli, M. Elbarbary, M. Blaivas, D.A. Lichtenstein, G. Mathis, A.W. Kirkpatrick, L. Melniker, L. Gargani, V.E. Noble, G. Via, A. Dean, J.W. Tsung, G. Soldati, R. Copetti, B. Bouhemad, A. Reissig, E. Agricola, J.-J. Rouby, C. Arbelot, A. Liteplo, A. Sargsyan, F. Silva, R. Hoppmann, R. Breitkreutz, A. Seibel, L. Neri, E. Storti, T. Petrovic, International Liaison Committee on Lung Ultrasound (ILC-LUS) for International Consensus Conference on Lung Ultrasound (ICC-LUS), International evidence-based recommendations for point-of-care lung ultrasound, Intensive Care Med. 38 (2012) 577591. doi:10.1007/s00134-012-2513-4.

[14] R.M. Lang, L.P. Badano, V. Mor-Avi, J. Afilalo, A. Armstrong, L. Ernande, F.A. Flachskampf, E. Foster, S.A. Goldstein, T. Kuznetsova, P. Lancellotti, D. Muraru, M.H. Picard, E.R. Rietzschel, L. Rudski, K.T. Spencer, W. Tsang, J.-U. Voigt, Recommendations for Cardiac Chamber Quantification by Echocardiography in Adults: An Update from the American Society of Echocardiography and the European Association of Cardiovascular Imaging, J. Am. Soc. Echocardiogr. 28 (2015) 1-39.e14. doi:10.1016/j.echo.2014.10.003.

[15] N. Girerd, P. Rossignol, Performing lung ultrasound at rest and/or after an exercise stress test to better identify high-risk ambulatory patients with heart failure, Eur. J. Heart Fail. (2017). doi:10.1002/ejhf.965.

[16] S. Coiro, P. Rossignol, G. Ambrosio, E. Carluccio, G. Alunni, A. Murrone, I. Tritto, F. Zannad, N. Girerd, Prognostic value of residual pulmonary congestion at discharge assessed by lung ultrasound imaging in heart failure, Eur. J. Heart Fail. 17 (2015) 11721181. doi:10.1002/ejhf.344.

[17] H. Dokainish, J. Nguyen, R. Sengupta, M. Pillai, M. Alam, J. Bobek, N. Lakkis, New, Simple Echocardiographic Indexes for the Estimation of Filling Pressure in Patients with Cardiac Disease and Preserved Left Ventricular Ejection Fraction, Echocardiography. 27 (2010) 946-953. doi:10.1111/j.1540-8175.2010.01177.x.

[18] M. Gheorghiade, G. Filippatos, L. De Luca, J. Burnett, Congestion in acute heart failure syndromes: an essential target of evaluation and treatment, Am. J. Med. 119 (2006) S3S10. doi:10.1016/j.amjmed.2006.09.011.

[19] S.D. Halpern, D.B. Taichman, Misclassification of pulmonary hypertension due to reliance on pulmonary capillary wedge pressure rather than left ventricular end-diastolic pressure, Chest. 136 (2009) 37-43. doi:10.1378/chest.08-2784.

[20] M.C. Scali, L. Cortigiani, A. Simionuc, D. Gregori, M. Marzilli, E. Picano, Exerciseinduced B-lines identify worse functional and prognostic stage in heart failure patients with depressed left ventricular ejection fraction, Eur. J. Heart Fail. (2017) n/a-n/a. doi:10.1002/ejhf.776.

[21] S.R. Ommen, R.A. Nishimura, D.G. Hurrell, K.W. Klarich, Assessment of Right Atrial Pressure With 2-Dimensional and Doppler Echocardiography: A Simultaneous Catheterization and Echocardiographic Study, Mayo Clin. Proc. 75 (2000) 24-29. doi:10.4065/75.1.24.

[22] M. D’Alto, E. Romeo, P. Argiento, A. Pavelescu, C. Mélot, A. D’Andrea, A. Correra, E. Bossone, R. Calabrò, M.G. Russo, R. Naeije, Echocardiographic Prediction of Pre- versus Postcapillary Pulmonary Hypertension, J. Am. Soc. Echocardiogr. 28 (2015) 108-115. doi:10.1016/j.echo.2014.09.004.

[23] N. Galiè, M. Humbert, J.-L. Vachiery, S. Gibbs, I. Lang, A. Torbicki, G. Simonneau, A. Peacock, A. Vonk Noordegraaf, M. Beghetti, A. Ghofrani, M.A. Gomez Sanchez, G. Hansmann, W. Klepetko, P. Lancellotti, M. Matucci, T. McDonagh, L.A. Pierard, P.T. Trindade, M. Zompatori, M. Hoeper, V. Aboyans, A. Vaz Carneiro, S. Achenbach, S. Agewall, Y. Allanore, R. Asteggiano, L. Paolo Badano, J. Albert Barberà, H. Bouvaist, H. Bueno, R.A. Byrne, S. Carerj, G. Castro, Ç. Erol, V. Falk, C. Funck-Brentano, M. 
Gorenflo, J. Granton, B. Iung, D.G. Kiely, P. Kirchhof, B. Kjellstrom, U. Landmesser, J. Lekakis, C. Lionis, G.Y.H. Lip, S.E. Orfanos, M.H. Park, M.F. Piepoli, P. Ponikowski, M.-P. Revel, D. Rigau, S. Rosenkranz, H. Völler, J. Luis Zamorano, 2015 ESC/ERS Guidelines for the diagnosis and treatment of pulmonary hypertension: The Joint Task Force for the Diagnosis and Treatment of Pulmonary Hypertension of the European Society of Cardiology (ESC) and the European Respiratory Society (ERS): Endorsed by: Association for European Paediatric and Congenital Cardiology (AEPC), International Society for Heart and Lung Transplantation (ISHLT), Eur. Heart J. 37 (2016) 67-119. doi:10.1093/eurheartj/ehv317.

[24] K. Sato, A.D.M. Grant, K. Negishi, P.C. Cremer, T. Negishi, A. Kumar, P. Collier, S.R. Kapadia, R.A. Grimm, M.Y. Desai, B.P. Griffin, Z.B. Popovi?, Reliability of updated left ventricular diastolic function recommendations in predicting elevated left ventricular filling pressure and prognosis, Am. Heart J. 189 (2017) 28-39. doi:10.1016/j.ahj.2017.03.022.

[25] P. Lancellotti, M. Galderisi, T. Edvardsen, E. Donal, G. Goliasch, N. Cardim, J. Magne, S. Laginha, A. Hagendorff, T.F. Haland, L. Aaberge, C. Martinez, A. Rapacciuolo, C. Santoro, F. Ilardi, A. Postolache, R. Dulgheru, A.D. Mateescu, C.C. Beladan, D. Deleanu, S. Marchetta, V. Auffret, E. Schwammenthal, G. Habib, B.A. Popescu, Echo-Doppler estimation of left ventricular filling pressure: results of the multicentre EACVI EuroFilling study, Eur. Heart J. - Cardiovasc. Imaging. 18 (2017) 961-968. doi:10.1093/ehjci/jex067.

[26] Y.M. Hummel, L.C.Y. Liu, C.S.P. Lam, D.F. Fonseca-Munoz, K. Damman, M. Rienstra, P. van der Meer, S. Rosenkranz, D.J. van Veldhuisen, A.A. Voors, E.S. Hoendermis, Echocardiographic estimation of left ventricular and pulmonary pressures in patients with heart failure and preserved ejection fraction: a study utilizing simultaneous echocardiography and invasive measurements, Eur. J. Heart Fail. (2017). doi:10.1002/ejhf.957.

[27] E. Donal, E. Galli, A.G. Fraser, Non-invasive estimation of left heart filling pressures: another nail in the coffin for E/e'?, Eur. J. Heart Fail. (2017). doi:10.1002/ejhf.944.

[28] G. Bedetti, L. Gargani, A. Corbisiero, F. Frassi, E. Poggianti, G. Mottola, Evaluation of ultrasound lung comets by hand-held echocardiography, Cardiovasc. Ultrasound. 4 (2006) 34. doi:10.1186/1476-7120-4-34.

[29] E. Agricola, C. Marini, Lung ultrasound predicts decompensation in heart failure outpatients: Another piece to the puzzle but still an incomplete picture, Int. J. Cardiol. 240 (2017) 324-325. doi:10.1016/j.ijcard.2017.04.111.

[30] L.W. Stevenson, J.K. Perloff, The limited reliability of physical signs for estimating hemodynamics in chronic heart failure, JAMA. 261 (1989) 884-888.

[31] S. Chakko, D. Woska, H. Martinez, E. de Marchena, L. Futterman, K.M. Kessler, R.J. Myerberg, Clinical, radiographic, and hemodynamic correlations in chronic congestive heart failure: conflicting results may lead to inappropriate care, Am. J. Med. 90 (1991) 353-359.

[32] R.E. Peverill, "Left ventricular filling pressure(s)" - Ambiguous and misleading terminology, best abandoned, Int. J. Cardiol. 191 (2015) 110-113. doi:10.1016/j.ijcard.2015.04.254. 


\section{Tables and Figures}

\section{Figure 1:}

\section{Panel A: Flow chart}

\section{Panel B: Method of B-line quantification.}

Panel 1: The four explored areas on the right hemithorax; Panel 2: Example of a frozen loop of lung ultrasonography with B-lines; Panel 3: The different analysed cut-offs. A: one bilateral positive zone (defined by $\geq 3$ B-lines in the same zone); B: two bilateral positive zones; $\mathrm{C}$ : Simplified B-line count: sum of all B-lines in the eight zones using two different cut-offs: $\geq 3$ or $\geq 8$ B-lines.

Panel C: ROC curves of the best indices and ASE/EACVI algorithm for the diagnosis of elevated LVEDP. 
Table 1: Baseline characteristics

\begin{tabular}{|c|c|c|c|c|}
\hline & $\begin{array}{c}\text { Overall } \\
n=81\end{array}$ & $\begin{array}{c}\text { LVEDP }<20 \text { mmHg } \\
n=53\end{array}$ & $\begin{aligned} & \text { LVEDP } \geq 20 \mathrm{mmHg} \\
& \mathrm{n}=28\end{aligned}$ & p-value \\
\hline Age (years) & $75(67-80)$ & $75(70-80)$ & $75(64-79)$ & 0.49 \\
\hline Sex, male & $55(67.9 \%)$ & $34(64.2 \%)$ & $21(75.0 \%)$ & 0.32 \\
\hline BMI $\left(\mathrm{kg} \cdot \mathrm{m}^{-2}\right)$ & $26(23-30)$ & $26(22-30)$ & $26(23-30)$ & 0.65 \\
\hline Smoking & $31(38.3 \%)$ & $20(37.7 \%)$ & $11(39.3 \%)$ & 0.89 \\
\hline Hypertension & $56(69.1 \%)$ & $37(69.8 \%)$ & $19(67.9 \%)$ & 0.86 \\
\hline Dyslipidaemia & $37(45.7 \%)$ & $24(45.3 \%)$ & $13(46.4 \%)$ & 0.92 \\
\hline Diabetes mellitus & $17(21.0 \%)$ & $6(11.3 \%)$ & $11(39.3 \%)$ & 0.003 \\
\hline Heart Failure & $41(50.6 \%)$ & $21(39.6 \%)$ & $20(71.4 \%)$ & 0.007 \\
\hline Coronaropathy & $40(49.4 \%)$ & $28(52.8 \%)$ & $12(42.9 \%)$ & 0.39 \\
\hline Severe Valvulopathy & $35(43.2 \%)$ & $24(45.3 \%)$ & $11(39.2 \%)$ & 0.96 \\
\hline Severe Aortic Stenosis & $24(29.6 \%)$ & $17(32.1 \%)$ & $7(25.0 \%)$ & \\
\hline$M R \geq 3 / 4$ & $9(11.1 \%)$ & $5(9.4 \%)$ & $4(14.3 \%)$ & \\
\hline$A R \geq 3 / 4$ & $2(2.5 \%)$ & $2(3.8 \%)$ & $0(0.0 \%)$ & \\
\hline AF history & $25(30.9 \%)$ & $18(34.0 \%)$ & $7(25.0 \%)$ & 0.41 \\
\hline paroxysmal & $12(14.8 \%)$ & $8(15.1 \%)$ & $4(14.3 \%)$ & 1.0 \\
\hline permanent & $13(17.3 \%)$ & $10(20.8 \%)$ & $3(10.7 \%)$ & 0.36 \\
\hline COPD & $6(7.4 \%)$ & $1(1.9 \%)$ & $5(17.9 \%)$ & 0.017 \\
\hline Renal insufficiency & $24(29.6 \%)$ & $13(24.5 \%)$ & $11(39.3 \%)$ & 0.17 \\
\hline \multicolumn{5}{|l|}{ Biology } \\
\hline MDRD (mL.min $\left.{ }^{-1}\right)$ & $68.2 \pm 21.3$ & $69.6 \pm 19.8$ & $65.5 \pm 24.0$ & 0.41 \\
\hline $\mathrm{Hb}\left(\mathrm{g} \cdot \mathrm{dL}^{-1}\right)$ & $13.5(12.2-14.8)$ & $13.6(12.4-14.8)$ & $13.4(12.2-14.6)$ & 0.69 \\
\hline NT-ProBNP (pg.mL $\left.L^{-1}\right)$ & $2013.9 \pm 2448.7$ & $1248.1 \pm 1603.2$ & $3332.7 \pm 3079.6$ & 0.014 \\
\hline \multicolumn{5}{|l|}{ Medications } \\
\hline B-blockers & $47(58.0 \%)$ & $30(56.6 \%)$ & $17(60.7 \%)$ & 0.72 \\
\hline Calcium channel blocker & $4(4.9 \%)$ & $2(3.8 \%)$ & $2(7.1 \%)$ & 0.61 \\
\hline ACEi/ARAII & $50(61.7 \%)$ & $35(66.0 \%)$ & $15(53.6 \%)$ & 0.27 \\
\hline Thiazide diuretic & $2(2.5 \%)$ & $1(1.9 \%)$ & $1(3.6 \%)$ & 0.49 \\
\hline Spironolactone & $9(11.1 \%)$ & $7(13.2 \%)$ & $2(7.1 \%)$ & 0.49 \\
\hline \multicolumn{5}{|l|}{ Physical examination } \\
\hline Heart rate $(\mathrm{bpm})$ & $73 \pm 15$ & $71 \pm 13$ & $75 \pm 19$ & 0.34 \\
\hline $\mathrm{SBP}(\mathrm{mmHg})$ & $135 \pm 22$ & $137 \pm 22$ & $131 \pm 22$ & 0.25 \\
\hline $\mathrm{DBP}(\mathrm{mmHg})$ & $74 \pm 13$ & $74 \pm 13$ & $74 \pm 14$ & 0.91 \\
\hline NYHA & & & & 0.0001 \\
\hline 2 & $59(72.8 \%)$ & $46(86.8 \%)$ & $13(46.4 \%)$ & \\
\hline $3-4$ & $22(27.2 \%)$ & $7(13.2 \%)$ & $15(53.6 \%)$ & \\
\hline Angina & $18(22.2 \%)$ & $15(28.3 \%)$ & $3(10.7 \%)$ & 0.070 \\
\hline Right heart failure clinical signs & $13(16.0 \%)$ & $5(9.4 \%)$ & $8(28.6 \%)$ & 0.052 \\
\hline Left heart failure clinical signs & $10(12.3 \%)$ & $2(3.8 \%)$ & $8(28.6 \%)$ & 0.003 \\
\hline
\end{tabular}

LVEDP: Left Ventricular End Diastolic Pressure; BMI: Body Mass Index; MR: Mitral regurgitation; AR: Aortic Regurgitation; AF: Atrial Fibrillation; COPD: Chronic Obstructive Pulmonary Disease; MDRD: Creatinine clearance by the MDRD formula (Modification of Diet in Renal Disease); Hb: Haemoglobin; NT-ProBNP: N-terminal-Pro Brain Natriuretic Peptide; ACEi: Angiotensin Conversion Enzyme inhibitors; ARAII: Angiotensin Receptor II Antagonists, SBP: Systolic Blood Pressure; DBP: Diastolic Blood Pressure 


\section{Table 2: Ultrasonographic and catheterization characteristics}

\begin{tabular}{|c|c|c|c|c|}
\hline & $\begin{array}{c}\text { Overall } \\
\mathbf{n}=81\end{array}$ & $\begin{array}{c}\text { LVEDP }<20 \mathrm{mmHg} \\
\mathrm{n}=53\end{array}$ & $\begin{array}{c}\text { LVEDP } \geq 220 \mathrm{mmHg} \\
\mathrm{n}=28\end{array}$ & p-value \\
\hline AF during TTE & $19(23.5 \%)$ & $12(22.6 \%)$ & $7(25.0 \%)$ & 0.81 \\
\hline Total B-lines & $3.0(0.0-12.0)$ & $1.0(0.0-4.0)$ & $17.0(9.0-24.0)$ & $<0.0001$ \\
\hline$\geq 3$ B-Lines & $45(51.9 \%)$ & $18(34 \%)$ & $24(85.7 \%)$ & $<0.0001$ \\
\hline$\geq 8$ B-lines & $27(33.3 \%)$ & $5(9.4 \%)$ & $22(78.6 \%)$ & $<0.0001$ \\
\hline 1 positive zone in each side* & $16(19.8 \%)$ & $1(1.9 \%)$ & $15(53.6 \%)$ & $<0.0001$ \\
\hline 2 positive zones in each side* & $10(12.3 \%)$ & $0(0.0 \%)$ & $10(35.7 \%)$ & $<0.0001$ \\
\hline \multicolumn{5}{|l|}{ LV systolic function } \\
\hline Preserved LVEF & $44(54.3 \%)$ & $34(64.2 \%)$ & $10(35.7 \%)$ & 0.015 \\
\hline $\operatorname{LVEF}(\%)$ & $52.0(34.0-61.4)$ & $53.0(43.0-62.0)$ & $39.0(30.0-55.3)$ & 0.027 \\
\hline GLS $(\%)$ & $-12.8(-18.0--8.6)$ & $-14.7(-18.4--10.0)$ & $-10.1(-16.6--7.8)$ & 0.054 \\
\hline LVESVi (ml.m²) & $31.8(19.5-50.6)$ & $27.8(18.8-46.0)$ & $46.2(29.5-63.3)$ & 0.043 \\
\hline LVEDVi & $69.0(50.4-86.7)$ & $63.3(47.6-81.0)$ & $74.0(59.6-92.8)$ & 0.103 \\
\hline Mitral S average $\left(\mathrm{cm} \cdot \mathrm{s}^{-1}\right)$ & $6.0(4.5-7.5)$ & $6.0(5.0-7.5)$ & $5.5(4.0-6.0)$ & 0.015 \\
\hline LV diastolic function & & 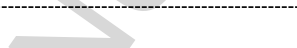 & & \\
\hline Mitral E $\left(\mathrm{cm} \cdot \mathrm{s}^{-1}\right)$ & $81(66-102)$ & $79(63-94)$ & $92(74-108)$ & 0.078 \\
\hline Mitral A $\left(\mathrm{cm} \cdot \mathrm{s}^{-1}\right)(\mathbf{n}=\mathbf{6 2})$ & $75(56-104)$ & $87(65-104)$ & $62(34-78)$ & 0.003 \\
\hline E/A ratio $(n=62)$ & $0.9(0.7-1.6)$ & $0.8(0.6-1.3)$ & $1.3(1.0-2.9)$ & 0.001 \\
\hline E wave, deceleration time (ms) & $186.0(148.4-259.0)$ & $216.0(164.0-305.0$ & $167.0(118.8-190.5$ & 0.004 \\
\hline $\mathrm{e}^{\prime} \operatorname{septal}\left(\mathrm{cm} \cdot \mathrm{s}^{-1}\right)$ & $5.8 \pm 2.5$ & $6.0 \pm 2.3$ & $5.5 \pm 2.7$ & 0.39 \\
\hline $\mathrm{e}^{\prime}$ lateral $\left(\mathrm{cm} \cdot \mathrm{s}^{-1}\right)$ & $7.0(5.0-10.0)$ & $8.0(5.0-10.0)$ & $6.5(4.5-8.5)$ & 0.31 \\
\hline Mitral e' average $\left(\mathrm{cm} \cdot \mathrm{s}^{-1}\right)$ & $6.5(4.5-8.0)$ & $7.0(5.0-8.5)$ & $5.8(4.3-7.8)$ & 0.18 \\
\hline Mitral E/e' septal & $15(11-21)$ & $13(10-19)$ & $20(14-26)$ & 0.017 \\
\hline Mitral E/e' lateral & $11(8-17)$ & $10(8-15)$ & $13(10-20)$ & 0.021 \\
\hline Mitral E/e' average of annuli & $12.5(9.3-18.3)$ & $11.6(8.6-15.9)$ & $15.6(11.4-22.0)$ & 0.014 \\
\hline $\mathrm{LV}$ isovolumic relaxation time $(\mathrm{ms})$ & $118.0 \pm 36.6$ & $125.0 \pm 35.6$ & $106.3 \pm 35.7$ & 0.035 \\
\hline $\operatorname{LAVi}\left(\mathrm{ml} \cdot \mathrm{m}^{-2}\right)$ & $48.5(33.4-62.3)$ & $45.7(33.3-62.3)$ & $49.1(36.4-62.6)$ & 0.51 \\
\hline \multicolumn{5}{|l|}{ RV systolic and diastolic functions } \\
\hline $\operatorname{RAVi}\left(\mathrm{ml} \cdot \mathrm{m}^{-2}\right)$ & $25.5(19.5-34.7)$ & $23.6(18.9-31.2)$ & $28.7(20.4-51.1)$ & 0.046 \\
\hline $\mathrm{RV}$ area change $(\%)$ & $42.0 \pm 12.9$ & $45.2 \pm 11.4$ & $36.0 \pm 13.7$ & 0.002 \\
\hline TAPSE & $22.0(18.0-25.0)$ & $23.0(19.0-26.0)$ & $20.5(16.0-24.5)$ & 0.14 \\
\hline RV free wall strain $(\%)$ & $-21.6 \pm 7.0$ & $-22.5 \pm 6.6$ & $-20.0 \pm 7.4$ & 0.15 \\
\hline RV IVA & $1.4(0.9-2.1)$ & $1.3(0.9-2.1)$ & $1.4(0.9-1.8)$ & 0.94 \\
\hline Peak TR velocity $\left(\mathrm{m} \cdot \mathrm{s}^{-1}\right)$ & $2.6 \pm 0.5$ & $2.5 \pm 0.4$ & $2.9 \pm 0.6$ & 0.0019 \\
\hline IVC dimension (mm) & $13.0(8.5-17.0)$ & $11.0(7.0-15.0)$ & $18.5(15.0-20.0)$ & $<0.0001$ \\
\hline PASP $(m m H g)$ & $34.0(26.0-45.0)$ & $30.0(25.5-36.5)$ & $50.0(30.0-60.0)$ & 0.0007 \\
\hline \multicolumn{5}{|l|}{ Catheterization } \\
\hline LVEDP $(\mathrm{mmHg})$ & $16.0(12.0-22.0)$ & $14.0(10.0-16.0)$ & $25.0(21.5-30.0)$ & $<0.0001$ \\
\hline LV-PreA $(\mathrm{mmHg})(\mathbf{n}=\mathbf{6 2})$ & $10.0(6.5-15.5)$ & $8.0(5.0-10.0)$ & $16.5(13.0-18.0)$ & $<0.0001$ \\
\hline LVESP $(\mathrm{mmHg})$ & $153.9 \pm 33.1$ & $155.6 \pm 33.2$ & $150.6 \pm 33.4$ & 0.53 \\
\hline
\end{tabular}

LVEDP: Left Ventricular End Diastolic Pressure; AF: Atrial Fibrillation; TTE: Trans-Thoracic Echocardiography; LVEF: Left Ventricular Ejection Fraction; GLS: Global Longitudinal Strain; LVESVi: Left Ventricular End Systolic Volume index; LVEDVi: Left Ventricular End Diastolic Volume index; LAVi: Left Atrial Volume index; RV: Right Ventricle; RAVi: Right Atrial Volume index; TAPSE: Tricuspid Annular Plane Systolic Excursion; IVA: IsoVolumic Acceleration; TR: Tricuspid Regurgitation; IVC: Inferior Vena Cava; PASP: Pulmonary Artery Systolic Pressure; LV-PreA: Left Ventricular pressure just before A-wave; LVESP: Left Ventricular End Systolic Pressure.

$*$ A positive zone is defined by $\geq 3 \mathrm{~B}$-lines in the same zone. 


\section{Table 3: Correlations with LVEDP and AUC in predicting an elevated}

\section{LVEDP}

\begin{tabular}{|c|c|c|c|c|c|c|}
\hline & $\begin{array}{l}\text { Spearman's } \\
\text { rho }\end{array}$ & AUC1* (CI 95\%) & $\begin{array}{l}\Delta A U C * * \\
(C I 95 \%)\end{array}$ & $\begin{array}{l}\text { p- } \\
\text { value } \\
\Delta \text { AUC }\end{array}$ & NRI (CI 95\%) & $\begin{array}{l}\text { p-value } \\
\text { NRI }\end{array}$ \\
\hline NT-ProBNP $(\mathbf{n}=49)$ & 0.355 & 86.7 (74.1 to 99.4$)$ & $0.8(-5.6$ to 7.2$)$ & 0.81 & 85.3 (33.7 to 136.9) & 0.001 \\
\hline \multicolumn{7}{|l|}{ Lung ultrasonography } \\
\hline Total B-Lines & 0.621 & 95.5 (90.0 to 100.0$)$ & 10.5 (3.7 to 17.3$)$ & 0.002 & 145.4 (113.0 to 177.9$)$ & $<0.0001$ \\
\hline$\geq 3$ B-Lines & 0.506 & $90.9(83.7$ to 98.1$)$ & $5.9(-0.1$ to 11.9$)$ & 0.053 & $89.2(49.5$ to 128.9$)$ & $<0.0001$ \\
\hline$\geq 8$ B-lines & 0.633 & $93.6(86.0$ to 100.0$)$ & $8.6(2.4$ to 14.8$)$ & 0.007 & $\mathbf{1 4 5 . 4}(113.0$ to 177.9$)$ & $<0.0001$ \\
\hline 1 positive zone in each side & 0.553 & 91.7 (83.8 to 99.7$)$ & $6.7(0.4$ to 13.1$)$ & 0.037 & $\mathbf{1 1 7 . 7}(80.7$ to 154.6$)$ & $<0.0001$ \\
\hline 2 positive zones in each side & 0.514 & $91.0(83.0$ to 99.0$)$ & $6.0(0.3$ to 11.7$)$ & 0.039 & 99.2 (59.9 to 138.5$)$ & $<0.0001$ \\
\hline \multicolumn{7}{|l|}{ LV parameters } \\
\hline LVEF & -0.117 & 84.5 (74.8 to 94.2$)$ & $-0.5(-1.2$ to 0.3$)$ & 0.22 & $\mathbf{- 1 2 . 8}(-58.5$ to 32.9$)$ & 0.58 \\
\hline GLS & 0.000 & 84.1 (74.3 to 93.9$)$ & $-0.1(-0.5$ to 0.3$)$ & 0.73 & $\mathbf{- 8 . 2}(-54.3$ to 37.9$)$ & 0.73 \\
\hline Mitral E & 0.209 & 85.4 (76.1 to 94.8$)$ & $0.5(-2.1$ to 3.0$)$ & 0.72 & $11.1(-32.2$ to 54.3$)$ & 0.62 \\
\hline E wave, deceleration time & -0.116 & $85.6(76.8$ to 94.5$)$ & $0.7(-3.2$ to 4.6$)$ & 0.74 & $16.2(-29.3$ to 61.7$)$ & 0.49 \\
\hline E/A ratio $(n=62)$ & 0.338 & $85.9(74.5$ to 97.3$)$ & $2.7(-0.5$ to 5.9$)$ & 0.097 & $\mathbf{6 5 . 2}(16.5$ to 113.9$)$ & 0.009 \\
\hline Ea lateral & -0.153 & 84.8 (75.3 to 94.4$)$ & $-0.1(-0.9$ to 0.6$)$ & 0.73 & $39.2(-5.7$ to 84.1$)$ & 0.087 \\
\hline Ea septal & -0.147 & 85.1 (75.6 to 94.6$)$ & 0.1 (-1.1 to 1.4$)$ & 0.84 & 44.7 (1.8 to 87.7$)$ & 0.041 \\
\hline Mitral Ea average & -0.164 & 84.8 (75.3 to 94.4$)$ & $-0.1(-0.6$ to 0.3$)$ & 0.57 & $\mathbf{- 2 0 . 8}(-66.2$ to 24.7$)$ & 0.37 \\
\hline Mitral annular E/Ea average & 0.316 & 85.8 (76.5 to 95.2$)$ & $0.9(-1.6$ to 3.3$)$ & 0.48 & 24.1 (-21.4 to 69.6) & $\mathbf{0 . 3 0}$ \\
\hline LV isovolumic relaxation time & -0.282 & 87.9 (78.9 to 96.9$)$ & $2.1(-3.2$ to 7.4$)$ & 0.44 & $\mathbf{5 3 . 3}$ (7.7 to 99.0$)$ & 0.022 \\
\hline LAVi & 0.088 & 84.9 (75.3 to 94.5$)$ & $-0.1(-1.3$ to 1.2$)$ & 0.91 & $\mathbf{- 2 . 7}(-47.9$ to 42.6$)$ & 0.91 \\
\hline \multicolumn{7}{|l|}{ RV parameters } \\
\hline RV fractional area change & -0.152 & $84.9(74.7$ to 95.1$)$ & $0.9(-3.1$ to 5.0$)$ & 0.65 & $21.4(-25.0$ to 67.7$)$ & 0.37 \\
\hline TAPSE & 0.010 & 84.8 (75.3 to 94.4$)$ & $-0.1(-0.9$ to 0.6$)$ & 0.73 & $8.6(-36.8$ to 54.1$)$ & 0.71 \\
\hline RV free wall strain & 0.012 & 86.9 (78.3 to 95.6$)$ & $0.1(-0.3$ to 0.6$)$ & 0.59 & $\mathbf{- 1 5 . 1}(-63.9$ to 33.6$)$ & 0.54 \\
\hline Peak TR velocity & 0.405 & $89.2(80.1$ to 98.2$)$ & $4.9(-1.1$ to 10.9$)$ & 0.11 & $\mathbf{1 0 2 . 0}(61.8$ to 142.2$)$ & $<0.0001$ \\
\hline IVC diameter & 0.347 & 90.5 (82.1 to 98.8$)$ & $7.1(0.3$ to 14.0$)$ & 0.042 & $135.9(100.2$ to 171.6$)$ & $<0.0001$ \\
\hline PASP & 0.397 & $90.6(82.3$ to 98.8$)$ & $6.3(0.2$ to 12.5$)$ & 0.043 & $\mathbf{1 0 1 . 4}(62.8$ to 140.0$)$ & $<0.0001$ \\
\hline 2016 ASE/EACVI algorithm & 0.175 & 83.0 (70.9 to 95.2$)$ & $-0.2(-1.6$ to 1.3$)$ & 0.82 & $45.0(-5.6$ to 95.6$)$ & 0.081 \\
\hline
\end{tabular}

*AUC1: AUC of clinical variables + parameter; $* * \Delta$ AUC: Difference between AUC1 and AUC of clinical variables alone 
NRI: Net Reclassification Index; AUC: Area Under the Curve; NT Pro-BNP: N-terminal pro Brain Natriuretic Peptide; LVEF: Left Ventricular Ejection Fraction; GLS: Global Longitudinal Strain; LAVi: Left Atrial Volume index; RV: Right Ventricle; TAPSE: Tricuspid Annular Plane Systolic Excursion; IVA: IsoVolumic Acceleration; TR: Tricuspid Regurgitation; IVC: Inferior Vena Cava; PASP: Pulmonary Artery Systolic Pressure 


\section{Highlights}

\section{Diagnostic accuracy of Lung Ultrasound for identification of elevated left ventricular filling pressure}

ASE/EACVI recommendation for the estimation of left ventricular filling pressure is quite complex and time consuming. B-lines, in lung ultrasound, could constitute an interesting tool for LVFP evaluation in clinical practice, but data regarding their association with invasive hemodynamics are lacking. The purpose of this study is to explore the diagnostic accuracy of B-lines to identify elevated left ventricular end-diastolic pressure (LVEDP).

About 81 adults with significant dyspnea (NYHA $\geq 2$ ) were prospectively analyzed. Clinical variables had a C-index of $79 \%$ to identify elevated LVEDP. Total B-lines number was higher in the elevated LVEDP group (1.0vs17.0, $\mathrm{p}<0.0001)$ and significantly increased diagnostic accuracy (C-index increase $=15.5 \%, p=0.004)$ and a net reclassification index (NRI=142.0, 108.5-175.6, $p<0.0001$ ) on top of clinical variables. In contrast, the 2016 ASE/EACVI recommendations did not significantly increase neither the reclassification nor the diagnostic accuracy. There is an important diagnostic capacity of B-lines to identify elevated elevated filling pressure and that is probably something to consider in our clinical routine. 


\section{A}

5 significant mitral stenosis

1 pulmonary fibrosis
6 patients did not und

6 patients did not undergo left heart catheterization

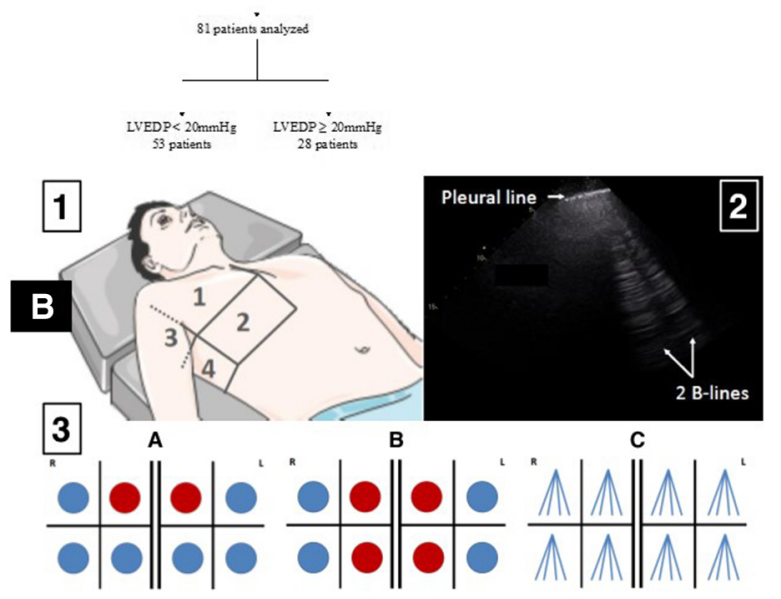

Negative zone
93 patients included

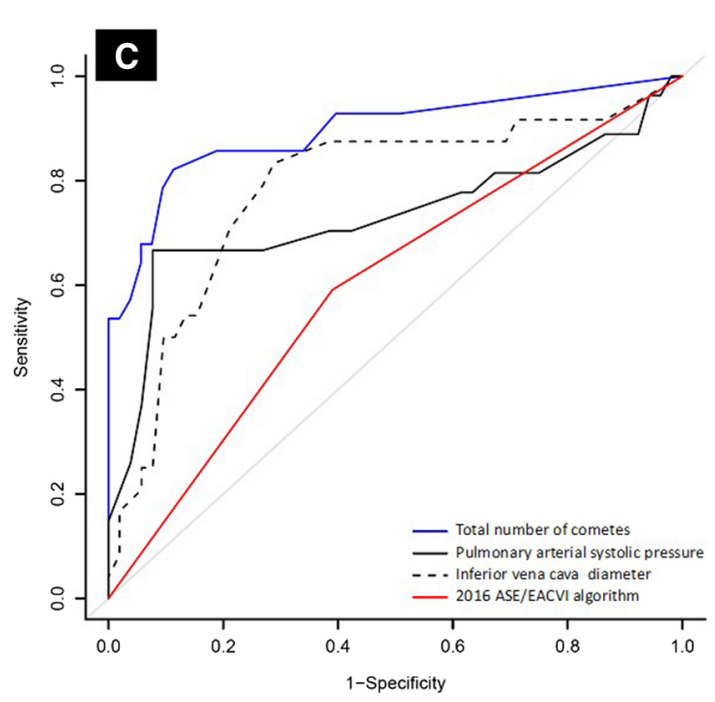

Figure 1 